Orbis Tertius, vol. XXIV, n 30, e139, noviembre 2019-abril 2020. ISSN 1851-7811

Universidad Nacional de La Plata

Facultad de Humanidades y Ciencias de la Educación

Centro de Estudios deeoría y Crítica Literaria

\title{
Carlos Aguirre y Ricardo D. Salvatore (eds.), Bibliotecas y cultura letrada en América Latina: siglos XIX Y XX. Lima, Fondo Editorial, 2018, 364 páginas
}

Bibliotecas y cultura letrada... reúne y pone en diálogo ensayos sobre la historia de la acumulación libresca en América Latina entre principios del siglo XIX y mediados del XX. Los aportes, producto del trabajo de investigadores formados en campos del saber disímiles, derivan de ponencias presentadas en el coloquio "Bibliotecas de las Américas: poder, capital cultural y circulación del conocimientos 1800-2000", desarrollado en el año 2014 en Argentina. Junto a estos trabajos — revisados y ampliados para la publicación -, se incorporan otros a pedido de los editores para procurar un panorama de mayor alcance. El libro está organizado en trece capítulos dispuestos en cuatro secciones: Bibliotecas y formación del Estado-Nación; Bibliotecas y cultura letrada; Bibliotecas, museos y prácticas cientificas y culturales y, por último, Bibliotecas, movilización politica y proyectos revolucionarios.

La publicación cubre un espacio de vacancia y significa una contribución sustancial para trazar un mapa de la formación y expansión de espacios de lectura en América Latina que contemple su estrecha vinculación con los procesos sociales, políticos y culturales que signaron la historia regional. A través de su lectura nos informamos acerca del recorrido que entre más de ciento cincuenta años transitaron algunas colecciones bibliográficas institucionales, personales y estatales de Perú, Argentina, Guatemala, El Salvador, Honduras, Nicaragua, Costa Rica, Brasil, México, Cuba, Puerto Rico y Uruguay. Aun cuando esta dispersión en tiempo, espacio y tipo de biblioteca supone trayectorias históricas bien diferenciadas, todas parecen estar atravesadas por al menos dos interrogantes comunes a los que se atiende a lo largo de la compilación. Por un lado, ¿̇a qué obedeció la temprana y creciente inquietud por reunir acervos documentales, en una América Latina con sus estados-nacionales en plena organización, con mercados editoriales escasamente afianzados, circuitos de lectura de incipiente formación y poblaciones en reciente proceso de alfabetización? Por otro, ¿en qué medida y de qué manera estos acervos acompañaron la progresiva consolidación de circuitos de lectura cada vez más vastos y diversos?

El interés por la constitución y el desarrollo de una cultura letrada elitista sustentó la determinación de distintos estados de América Latina — tanto en épocas coloniales como, aún más decisivamente, en períodos de formación de nuestros estados independientes - por crear y/o financiar total o parcialmente bibliotecas de carácter multidisciplinar y también especializadas. Asimismo, aunque en menor medida a juzgar por la muestra que se reúne en Bibliotecas y cultura letrada..., hubo esfuerzos oficiales que buscaron promover las bibliotecas como espacios para la instrucción y difusión cultural entre sectores más amplios.

Dentro de aquellas destinadas a grupos minoritarios de la sociedad, el ejemplo más extremo corresponde a la Biblioteca Real de Portugal, trasladada a la nueva sede del gobierno en Brasil hacia 1810-1811 y transferida, luego de declarada la independencia brasileña en 1822, a su flamante monarquía constitucional. En su ensayo, Lilia Moritz Schwarcz resalta el valor no sólo económico sino también - y quizá fundamentalmente - simbólico que se otorgó a este acervo en tanto ícono de la acumulación de conocimiento y erudición al que sólo se podía acceder con permiso real. Por su parte, María Margaret Lopes, que trabaja con la Biblioteca del Museo Nacional de Río Janeiro, aporta información relevante para comprender cómo gradualmente - el Estado asumió la responsabilidad de acompañar los procesos de consolidación de campos 
del conocimiento a través del arreglo y sostén de colecciones bibliográficas especializadas. Creado en 1819 bajo el gobierno portugués, a mediados del siglo XIX el Museo aún no disponía de las obras escritas esenciales para la producción de conocimientos científicos propios, situación que se logró revertir gracias a las incansables negociaciones de sus directores. En Argentina se observó un panorama similar: el crecimiento de la estructura estatal que tuvo lugar avanzado el siglo XIX fue acompañado de diferentes proyectos que procuraron conformar ámbitos públicos al margen de los círculos informales y privados en los que las élites científicas pudieran desarrollar su sociabilidad y contribuir al progreso y la modernización nacionales. Entre ellos, el proyecto desplegado por Vicente Quesada al frente de la Biblioteca Pública de la Provincia de Buenos Aires desde 1871 hasta 1879. Al respecto, Pablo Buchbinder entiende el empeño del intelectual por organizar valiosas colecciones científicas y por limitar su uso a "los estudiosos" (p. 158), como parte de los intentos por superar la debilidad estatal de entonces que hacía depender el cultivo de las disciplinas humanísticas del patrimonio y los acervos bibliográficos personales. Por el mismo derrotero continuó la dirección de Paul Groussac una vez que, en 1884, la Biblioteca Pública bonaerense se convirtió en Biblioteca Nacional. Al igual que su predecesor — según nos informa Paula Bruno-, el francés la concibió como directamente funcional al desarrollo intelectual del país. Por su parte y, pese a lo que pudiera indicar el sentido común, esta orientación institucional no viró con la llegada del peronismo al poder. Como señala Flavia Fiorucci, la permanencia de Martínez Zuviría en el puesto de Director (quien había asumido en 1931) junto a la marginalidad de la Biblioteca Nacional en relación a otros espacios lectores que acompañaron decisivamente la democratización del acceso a la cultura, fueron motivos determinantes para que la gestión bibliotecaria continuara enfocada en el servicio a las tareas de investigación. No obstante ello, la expansión del público lector y de los circuitos de lectura que se había alcanzado en Argentina durante el siglo XX hacía llegar sus efectos a los recintos de la Biblioteca Nacional: allende el ahínco de su Director por disuadir la concurrencia de sectores populares, estos asistían con más frecuencia que los eruditos a los que se procuraba atraer. En Perú, la administración de Palma (1883-1912) — de la que nos habla Pedro Guibovich Pérez - también tendió a hacer de la Biblioteca Nacional "un centro de estudio", "un espacio para el cultivo de la inteligencia por los ciudadanos instruidos" (p. 51), bien diferenciado de las bibliotecas populares o municipales que funcionaban como ámbitos para la pedagogía de las masas. El proceso de fundación de bibliotecas nacionales en Centroamérica obedeció a preocupaciones e intereses similares a aquellos que hemos señalado en relación a sus pares latinoamericanas, aunque inició un poco más tardíamente y sus colecciones crecieron con mayor lentitud. Iván Molina Jiménez reúne información sobre los repositorios nacionales de Guatemala, El Salvador, Honduras, Nicaragua y Costa Rica y señala que su organización inicial coincidió con el ascenso de los gobiernos liberales en la región entre 1870-1914 y la puesta en marcha de reformas que propendieron al progreso y la modernización de cada país. Así, se les entendió como centros de instrucción que contribuirían a construir y propagar una cultura nacional y que estarían al servicio del adelanto intelectual de cada nación. Sin embargo, la escasez bibliográfica, la ausencia de obras locales y la carencia de políticas de adquisición — que pronto manifestaron estas instituciones- pusieron en evidencia sus limitaciones para alcanzar los objetivos originales. También con intenciones nacionalistas y fines eruditos fue que se desarrolló el fondo de la Biblioteca Nacional de Antropología e Historia de México, la última de las mencionadas en el libro, perteneciente a la órbita oficial y destinada a una porción minoritaria de la sociedad. Gracias a la investigación de Christina Bueno sabemos que su colección primaria fue el producto del esfuerzo gubernamental por reunir todo el material escrito disponible sobre México y su pasado, a fin de que los investigadores tuvieran herramientas con que construir un relato histórico sobre el país, al tiempo que contribuirían a la consolidación de una cultura científica nacional.

Por otro lado, y ya a mediados del siglo XX, encontramos en el ejemplar la mención a dos espacios de carácter estatal cuyos proyectos bibliotecarios — aunque claramente diferenciados - fueron pensados para el servicio de amplios sectores sociales: la Biblioteca Nacional de Cuba y la Comisión Nacional de Bibliotecas Populares argentina (CONABIP). Ricardo Salvatore restituye la historia de la primera en el contexto de 
la Revolución (1959-1967) y destaca cómo, de ser un depósito de libros "vacío de lectores" (p. 315), se transformó en un elemento crucial para democratizar el acceso a la lectura y promover la cultura socialista en la isla. Flavia Fiorucci, en tanto, recupera el trabajo de la CONABIP durante los dos primeros mandatos peronistas y afirma que no sólo se continuó con el proyecto original de difusión de la lectura entre el pueblo por medio del apoyo económico a bibliotecas populares sino que, además, se dio a esta política pública nuevos bríos que intensificaron su alcance y efectos.

El desarrollo de colecciones oficiales en América Latina fue acompañado por un crecimiento paralelo de importantes acervos personales. De ellos, en el volumen se analizan los casos del general Bartolomé Mitre (1820-1906), el filólogo y arqueólogo Samuel Alexander Lafone Quevedo (1835-1920) y el de otros veintisiete intelectuales de Perú que desenvolvieron sus actividades durante el siglo XX. Respecto de las bibliotecas pertenecientes a los dos letrados y funcionarios de Argentina, Máximo Farro señala que se constituyeron como valiosos espacios de trabajo y también de sociabilidad científica. Frente a la corriente dificultad con que se enfrentaban el común de los intelectuales al momento de acceder a colecciones especializadas que permitieran el desarrollo de sus investigaciones y a la escasez de políticas públicas en la materia, esta clase de repositorios resultó clave para constitución de una cultura científica nacional. De igual manera, la deficiencia de las bibliotecas peruanas de jurisdicción oficial para atender las necesidades informacionales de sus investigadores fue una de las principales razones que, al entender de Carlos Aguirre, motivó la acumulación bibliográfica por parte de numerosos letrados de Perú entre quienes se cuentan los veintisiete analizados por el autor. Para quienes debían avanzar en sus estudios y en la producción de conocimientos — en particular durante la primera mitad del siglo XX - generar colecciones de trabajo propias fue, entonces, una cuestión de necesidad. De allí que formaran parte de estos acervos preciadas secciones especializadas y piezas bibliográficas únicas.

En un terreno intermedio entre los repositorios personales y los de carácter estatal, en el volumen se trabajan otros que resulta complejo etiquetar. Flores Ramos examina el devenir de dos de ellos surgidos en Puerto Rico en un contexto colonial: el Gabinete de Lectura de Ponce y la Biblioteca Insular de San Juan. Mientras que el primero nació por el interés de la intelectualidad puertorriqueña como un espacio lector de élite y, más tarde, contó con apoyo oficial a cambio de ampliar el público destinatario; el surgimiento de la segunda obedeció al interés del gobierno de ocupación norteamericano por controlar la educación popular y se sostuvo, sin embargo, por un sistema de suscripción que no logró prosperar. Para finalizar, Alfredo Alzugarat analiza la función cumplida por tres bibliotecas carcelarias de Uruguay entre 1968-1974. Organizadas originalmente con relativa autonomía por los mismos presos políticos como material de estudio para las escuelas de cuadros que establecieron dentro de los penales, tras el golpe de 1973 y las consecuentes censuras, se transformaron en pequeñas bibliotecas clandestinas que, más tarde y debido a la extrema represión, también dejaron de circular. Así, el acceso de los presos a la palabra escrita llegó a verse limitado a las obras seleccionadas por los militares y dispuestas en las bibliotecas centrales de cada prisión.

Las diversas historias reseñadas se encuentran atravesadas por, al menos, un punto en común: la creencia en la capacidad incuestionable de la palabra escrita, bien para la construcción de 'lo nacional', para la educación de las masas, para alcanzar el progreso y la modernización de naciones recientemente independizadas, para acompañar la consolidación de campos del saber o para la misma emancipación intelectual. En este sentido, si volvemos sobre los interrogantes apuntados al principio, podemos sostener que fue el valor otorgado a las colecciones bibliográficas como herramientas de progreso, vinculadas a la instrucción de los ciudadanos y al desarrollo científico de los países, lo que impulsó el despliegue de bibliotecas de diversa índole en una América Latina con sus estados nacionales en pleno proceso de re-organización. Asimismo, esa expansión bibliotecaria llegó a ser determinante para la creciente formación y diversificación de circuitos lectores. Estas primeras respuestas que aporta la lectura del tomo abren, a su vez, nuevas preguntas: ¿qué derrotero siguió la formación de espacios lectores en las naciones no contempladas por la compilación? ¿Qué otros repositorios integraron 
el mapa bibliotecario de la región entre los siglos XIX y XX? ¿Cómo construir la postergada Historia de las Bibliotecas de América Latina?

Bibliotecas y cultura letrada... invita a desempolvar fuentes aún no consultadas y continuar la recuperación sistemática de nuestras historias como organizadores de colecciones bibliográficas, primero a nivel nacional, luego en el marco de un gran trabajo integrador que restituya a Latinoamérica esta porción de su vibrante pasado cultural. 